\title{
IMIA Presidential Retrospectives on Medical Informatics
}

\author{
M.J. Ball', J.H. van Bemmel' ${ }^{2}$ S. Kaihara ${ }^{3}$ \\ IBM Research Center for Healthcare Management and Johns Hopkins School of Nursing, Baltimore, USA \\ 2Erasmus Medical Center and Erasmus University Rotterdam, Rotterdam, the Netherlands \\ ${ }^{3}$ Postgraduate School, International University of Health and Welfare, Tokyo, Japan
}

\section{Introduction}

Established in 1967 as a Technical Committee 4 (TC-4) of the International Federation for Information Processing (IFIP), the International Medical Informatics Association (IMIA) turns 40 in 2007.

In looking back over those 40 years, we can see that IMIA has evolved to be the key international organization in the field of biomedical and health informatics for the promotion of informatics in health care and biomedical research, the advancement of international cooperation, the stimulation of research, development and education, and the dissemination and exchange of information [1-5]. Inherent in this mission was and still is to bring together, from a global perspective, healthcare practitioners, academics, scientists, researchers, vendors, consultants and suppliers in an environment of cooperation and sharing.

MEDINFO, IMIA's triennial world congresses for biomedical and health informatics became the centerpiece of a broad range of IMIA conferences (Table I). The IMIA Yearbook of Medical Informatics, founded in 1992, showcases contributions from the best state-of-the-art research, and has become one of the most visible and valuable IMIA publications (Table II), drawing on, and adding to the great and impressive variety of books, proceedings and journal articles produced under IMIA sponsorship.
Invited by the editors of the current IMIA Yearbook of Medical Informatics, three former presidents of IMIA from three continents, the authors of this article, have been invited to give a personal retrospective on the world's largest organization in medical informatics. Our reports on IMIA, on our presidencies, and on the still growing field of medical informatics can be found in the next sections. We are aware that there is overlap in our reports. In accordance with the editors, this overlap was regarded as useful for documenting differing aspects of IMIA presidential retrospectives on medical informatics.

\section{Shigekoto Kaihara, Japan, IMIA President 1986-1989}

When I became the President of IMIA in 1986, I was confronted with the following two issues that required a certain amount of consideration. First, whether medical informatics was in fact an independent scientific entity, and second, how it could be transformed into an international organization, as the name indicated.

\subsection{Independent Organization}

In 1986, based on an organizational perspective, IMIA was not an independent organization; instead, it was a part of the International Federation of In- 


\section{Table 1 MEDINFO conferences}

\begin{tabular}{|lll|}
\hline & \multicolumn{2}{c|}{$\begin{array}{c}\text { MEDINFO conferences } \\
\text { IMIA's triennial world congresses on medical informatics }\end{array}$} \\
\hline 1974 & Stockholm & Sweden \\
1977 & Toronto & Canada \\
1980 & Tokyo & Japan \\
1983 & Amsterdam & The Netherland \\
1986 & Washington & United States \\
1989 & Beijing/Singapore & \\
1992 & Geneva & Switzerland \\
1995 & Vancouver & Canada \\
1998 & Seoul & South Korea \\
2001 & London & Great Britain \\
2004 & San Francisco & United States \\
2007 & Brisbane & Australia \\
\hline
\end{tabular}

Table II IMIA Yearbooks of Medical Informatics

\begin{tabular}{|ll|}
\hline & \multicolumn{1}{c|}{$\begin{array}{c}\text { IMIA Yearbooks of Medical Informatics } \\
\text { Topics }\end{array}$} \\
\hline 1992 & Advances in an Interdisciplinary Science \\
1993 & Sharing Knowledge and Information \\
1994 & Advanced Communications in Health Care \\
1995 & The Computer-based Patient Record \\
1996 & The Integration of Information for Patient Care \\
1997 & Computing and Collaborative Care \\
1998 & Health Informatics and the Internet \\
1999 & The Promise of Medical Informatics \\
2000 & Patient-centered Systems \\
2001 & Digital Libraries and Medicine \\
2002 & Medical Imaging Informatics \\
2003 & Quality of Health Care: Informatics Foundations \\
2004 & Towards Clinical Bioinformatics \\
2005 & Ubiquitous Health Care Systems \\
2006 & Assessing Information Technologies for Health \\
2007 & Sustainable Health Systems through Biomedical Informatics \\
\hline
\end{tabular}

formation Processing (IFIP) and was known as the Special Interest Group (SIG) of IFIP. As a result, I was required to attend not only the IMIA Board meetings but also the annual IFIP General Assembly (GA) meetings, which were usually held in the European countries. Despite the fact that it was inconvenient for me to be present at both meetings, since I was based in Japan, which is located in the Far East, I believed that attending the IFIP GA meeting to report the activities of IMIA and get the approval for its budget, was an important duty as the President of the IMIA. During these meetings, I re- alized that the IFIP GA was more interested in IMIA's budget as opposed to its scientific contents. Although both organizations dealt with information processing, their scientific interests differed considerably; more specifically, IFIP was involved in computer technology, while IMIA was concerned with its medical applications. Consequently, I thought that it would be more beneficial, if both organizations became independent from an organizational standpoint, but continued to maintain a strong scientific relation for subjects of common interest.

Fortunately, one of the board members of IFIP, a Danish representative, Mr. Aage Melbye, realized the potential of this idea, and together with him, I decided to present a proposal to the IFIP GA to materialize this idea. However, owing to the fact that we were based in different countries and email systems had not yet been developed, we found it difficult to discuss the proposal in detail. Hence, we utilized the short time that was available to us when I was in Copenhagen as a transit passenger. I can still recall the day we met and wrote the proposal at Tivoli garden cafeteria. Subsequently, we submitted the proposal to the IFIP GA in 1987. At the IMIA board meeting in Geneva, we were informed via telegram that the proposal had been approved by IFIP. Thus, in truth, IMIA became an independent organization at this meeting.

\subsection{International Organization}

As mentioned previously, the second issue concerned the internationality of the organization. In 1986, IMIA was still a European-based organization. This seemed perfectly reasonable since the organization was initiated by the efforts of European scientists such as Prof. François Grémy, Jan Roukens and 
Jos Willems. Most of the administrative and scientific activities such as board meetings and working conferences were held in European countries. Moreover, at the time, we implicitly believed that medical informatics could only be applied to developed countries. In fact, a majority of the members of IMIA were from such countries. However, Dr. Salah Mandil, from WHO, always stated that medical informatics should also be applied to developing countries since it has the potential of tackling their health issues.

Since I held the same opinion as Dr. Mandil did, I decided to test this concept by organizing as many activities as possible in those countries, where informatics was in a nascent stage. I was extremely pleased when the People's Republic of China suggested that the 1989 MEDINFO should be held in Beijing. Since we were unaware of the situation in China, we debated and discussed this proposal at length. Eventually, the IMIA General Assembly decided to accept this invitation.

Further, in order to make IMIA a more international organization, I planned to organize IMIA's spring board meetings in countries where there had never been any IMIA activity. I believed that the presence of IMIA board members would help in attracting the attention of health related personnel toward medical informatics.

Subsequently, the IMIA board meetings were held in Beijing, East Berlin, and Rabat in Morocco with the help of Mr. Ouyang Zhineng, Prof. Josef Michel, and Prof. Roger Salamon, respectively. Further, in 1990, when Dr. Marion Ball was President of IMIA, I helped her to organize a meeting in Tbilisi in the Georgian Republic with the help of Prof. Gayos Sh Vasadze. Although attending these meetings required considerable travel, in general, they were successful. In fact, we even enjoyed the traveling.
However, the Beijing MEDINFO in 1989 was particularly eventful. The organizing committee chaired by $\mathrm{Mr}$. Ouyang worked extremely hard for two and half years in order to make this conference a success, this being the first of its kind in the country. Given the amount of effort invested, everyone was certain of its success and was looking forward to it. On June 4, 1989, I visited Beijing to have the final preparatory discussion with the organizing committee. I was also supposed to meet with the Minister of Health, Mr. Chen Minzhan, and the members of the organizing committee over dinner at the Beijing Hotel in front of Tiananmen Square. At dinner, we drank Maotai liquor and toasted for the success of the coming MEDINFO. However, just before we left the hotel, Mr. Chen Minzhan received a telephone call. He then approached me and said ,There might be an unpleasant event tonight, but since this is just an internal matter, you do not have to worry". Unsure of what he meant, I went back to my hotel, which was about $1.5 \mathrm{~km}$ from Tiananmen Square.

The Tiananmen Square Incident took place that very night. In the morning, although I felt something unusual in the atmosphere, I did not have the means to determine what had happened. The television repeatedly broadcasted some message, but I was unable to understand it, and the hotel desk seemed ignorant to any event or incident. Later that morning, I received a phone call from Mr. Ouyang and he recommended that I fly back to Japan. In fact, he was kind enough to drive me to the airport. During our drive, we discussed various pleasant issues such as the plans for the October MEDINFO. We could not have imagined that this was the beginning of something extremely unfortunate. Soon after I reached Japan, I began receiving over a hundred letters from participants stating that they would be unable to attend the MEDINFO in China and that IMIA should hold the meeting in some other city. Following which, I sent a letter to Mr. Ouyang inquiring, whether the conference venue should be changed. However, contrary to my expectation, the Chinese organizing committee insisted that the conference should be held in Beijing as scheduled. While discussing this with Mr. Ouyang over the phone, I could sense that he was aware of the problem, but was unable to officially disclose it. After considerable deliberation, I proposed that the first part of the conference should be held in Beijing as scheduled, but that the second part will be held in another country for those, who would be unable to participate in the Beijing MEDINFO. Mr. Ouyang finally accepted my proposal.

Fortunately, Dr. KC. Lun, based in Singapore, had been an acquaintance of mine for a long time. I requested his assistance in organizing the second part of MEDINFO in Singapore. Although there were only three months at hand till MEDINFO, Dr. Lun assured me that he would do his best. I was extremely grateful to him for his support and assurance. Despite the shortness of time, Dr. Lun reserved an excellent conference site for the Singapore MEDINFO in December; work for the coming conference commenced in full swing. However, we were still confronted with a complex problem. Since many participants had already paid their conference fees to the Bank of China, I requested Mr. Ouyang to transfer this amount to a bank in Singapore, if the participants decided to go to the Singapore MEDINFO. Despite the fact that such a transaction would have been extremely complicated at the time, $\mathrm{Mr}$. Ouyang resolved this issue with sincerity and succeeded in transferring the fees amount to a Singaporean bank. 
The Beijing MEDINFO as well as the Singapore MEDINFO were equally successful. More than 600 participants attended each conference. Apart from Dr. Phil R Manning, the chairperson of the Program Committee, and me, all other participants attended only one of the two meetings. However, papers presented at both the conferences were included in the same proceedings edited by Barry Barber, Dexian Cao, Dulie Qin, and Gustav Wagner, which symbolized that the two conferences were in fact just one.

This was an extremely critical time for IMIA. If we had failed to deal with the issue in an appropriate manner, there was the impending danger of disintegrating IMIA. I am proud to state that we were able to avert this crisis as a result of the mutual trust and friendship among the IMIA members. According to a Japanese proverb, „After the rain, the ground becomes even harder"; in other words, after overcoming this difficult situation, the organization became stronger. I firmly believe that after this experience, IMIA has evolved into a strong international organization based on the mutual trust and friendship of all the members across the globe.

\subsection{Acknowledgements}

Through the IMIA activities, I had the opportunity to get acquainted with many wonderful people. In addition to the people that I have already mentioned, I would like to express my gratitude to Dr. Donald A. B. Lindberg, Prof. Jan van Bemmel, Dr. Hans Peterson, Mr. John Flint, Dr. Marion Ball, Dr. Ab Bakker, Prof. Jean-Raoul Scherrer, Dr. Jana Zvárová, Prof. Kathy Hannah and Prof. Otto Rienhoff, among others, for the support that they provided during my presidency. I will always treasure the friendships that I have forged during my tenure. Last, but not the least, I would like to sincerely thank IMIA for providing me with this marvelous opportunity.

\section{Marion J. Ball, USA, IMIA President 1992-1995}

From the beginning of my career in health informatics, I have advocated the use of information technology as an enabler for transforming health care. Today the power and the promise of technology are greater than ever before. This is to the good, because we face greater perils than we have in the past.

\subsection{Crisis and Challenge}

Health care is in crisis around the globe. In developed countries, total health care expenditures are increasing twice as rapidly as economic growth, yet the health care crisis involves much more than dollars. The United States spends more on health care than any other country, yet is ranked 37 th in overall health care performance by the World Health Organization. Globally, the crisis is fueled by shifting demographics and resulting fundamental changes in health care. Consider chronic conditions, for example. In developed nations, increased life expectancy (up 68.5 years in 1960 to 77.8 years in 2003) has been accompanied by a rise in the incidence of chronic diseases and the expense of treating them to prevent complications over time. Yet chronic disease is a much greater problem. In developing and least developed nations, chronic conditions are increasingly prevalent. Experts put the loss of income to China over the next ten years as a result of heart disease, stroke, and diabetes at US\$ 550 billion, and pre- dict chronic diseases will be a leading cause of death in Nigeria by 2015. In a global environment, emerging infectious diseases are of grave concern to developed nations and further strain resources in developing countries still fighting existing infectious diseases. Other factors are at work as well, including the growth of consumerism (something we could alternately call patient involvement in managing their own care) in the United States, the obesity epidemic in ten of the world's developed countries, and the need for basic public health measures in least developed nations.

I have long believed that enabling technologies can transform health care, if we also bring about simultaneous, inter-related changes in and by health care systems, consumers, society, and government. In the patient safety reports it published earlier in this decade, the Institute of Medicine quoted Goethe, „Knowing is not enough; we must apply. Willing is not enough; we must do." [6]. This commitment to knowledge and to action is essential to the magnitude of change transforming health care entails. Today governmental and private sector organizations around the globe are responding to this call to action.

This call for change has long been championed by the international informatics community. In April 1979, international informaticians concluded a working conference on Hospital Information Systems: An International Perspective on Problems and Prospects, sponsored by IFIP, the International Federation on Information Processing ([7], Table III). More precisely, it was Technical Committee 4, or TC-4, the forerunner of IMIA, that addressed computing in health care within IFIP, where Dr. Donald A.B. Lindberg represented the United States for many years. As program chairman, I had the 
privilege of summarizing the conferees' findings, noting that „In these five days we have ... melted national boundaries. We have worked well together. In our exchange of ideas and our sense of common purpose, I believe that we have taken one more step to assure that there will persist this new interdisciplinary field in which medicine and a variety of sciences unite." [8].

This working conference in Capetown, South Africa, was the forerunner of Working Group 10, Health Information Systems (when IMIA became independent of IFIP), and the model for other working conferences to follow, including the 1993 conference I co-chaired in Washington, DC, on the Health Care Professional Workstation [9]. The 1979 meeting in South Africa took me back to where I was born. MEDINFO 2010, which will also be in Capetown, will take me back again, to where some of my longest standing professional relationships began. These were established during the two-year planning for the 1979 conference.

With those early leaders in Capetown, I shared with my aspirations to assess the state of the art of hospital information systems, to identify barriers and solutions to them, and, finally, to begin applying new knowledge. To this end, the conferees recommended that IFIP, then IMIA, establish a working group on Health Care Information Systems. In my closing remarks as program chair, I summarized our findings. In 1979, with remarkable prescience, they stressed critical areas that health care as a whole has taken many years to acknowledge:

1 The importance of behavioral and people issues in effecting technical and structural change

2 The centrality of the patient to health care („Health care professionals exist for the purpose of serving the patient.")
Table III Committee members at the 1979 Capetown Working Conference

\section{Capetown Working Conference}

Scientific Program Committee

M.J. Ball, Pennsylvania, USA, chair

Prof. Dr. med. G. Griesser, West Germany

Mr. G.L. Hammon, Texas, USA

Mr. S. Huesing, Alberta, Canada

Dr. S. Raymond, Pennsylvania, USA

Dr. R.H. Shannon, Washington State, USA

Dr. E. Simson, New York, USA

Dr. A. van der Werff, the Netherlands

Proceedings Editor

Dr. R.H. Shannon

Local Organizing Committee

Dr. L.K. Bredell, Tygerberg Hospital, co-chair

Dr. J. Kane Berman, Groote Schuur Hospital, co-chair

Mr. N. Esterhuyse, Cape Provincial Administration

Mr. R. Simon, Computer Society of South Africa

Dr. H. Steyn, Computer Society of South Africa

Miss C. Vader, Groote Schuur Hospital

Miss C.M. Hayward, Secretariat, South African

Medical Research Council

Miss J.J. van Schalkwyk, Secretariat, South African

Medical Research Council

Rapporteurs

Lyn Hanmer

Hester-Marie Malan

Mervin Cohen

Peter Booth

James Higginson

Derek Maree

Roger White

Dereck de Kock

3 A focus ,not so much the technological capability, but technological performance conjoined with medical, nursing and administrative staff's perceived need to improve the effectiveness of their components of Health Care."

4 The need for health information systems that ,will allow education to be linked to real events in practice at the time that the physician is preparing his diagnostic and therapeutic plans. When this goal is reached, patient care will be immensely improved." [8].
Today, almost 30 years later, international and national calls for action are targeting these four areas. In the United States, the 10-year goal of an electronic health record for all Americans in 2014 is driving the move to a new health system for the 21 st century - safe, effective, patient-centered, timely, efficient, and equitable - defined by the Institute of Medicine (IOM) in its groundbreaking quality reports ([6], p. 6). The federal government is encouraging industry to collaborate in realizing this goal, to ensure that Americans receive „care that meets their needs and is based on the best scientific evidence" ([6], p. 6 ) and industry is responding. Their response has been wide-ranging, from support for the Technology Informatics Guiding Education Reform (TIGER, [10]), an initiative defining an agenda and actions steps for the nursing profession, to development of visionary agendas for health care. One such vision [11] issues a call to action with three prescriptions - transform value, transform patient responsibility, and transform care delivery - that all map to the issues I summarized back in 1979. When I consider the meeting at Capetown, I am still amazed at the time that passed before understanding was widespread that changing systems means changing behaviors, and requires acknowledging and addressing human factors [12]. It was not until the 1990s that the so-called 'soft sciences' were accepted into the medical informatics world, due in part to the work begun at the 1993 Working Group Conference on Organizational Impact of Informatics held in Cincinnati, Ohio, USA, under the able leadership of Nancy Lorenzi, now IMIA President [13]. Now known as IMIA WG 13, Organizational and Social Issues, this group helped drive home the message that 'people count' and ignoring 'people issues' was in large part for the ,brief 
history of medical informatics ... [being] littered with horror stories." [13]. Much remains to be done to ease user acceptance of health information technology (HIT). Physician adoption can still be difficult, and integration of HIT into the workflow of other health professionals, notably nurses, has received short shrift until recently. The cognitive sciences offer avenues to understand decision making, avoid errors, and improve the quality and value of care. We are only now starting to address not only the work flow but 'thought flow' as a concept of behavioral change. As the Capetown conferees acknowledged almost three decades ago, transforming the health care system is much more than a technical challenge. Having begun my working career as a teacher of high school mathematics, I took special interest in the recommendation for educational reform at Capetown and still pursue this goal, most recently in the Technology Informatics Guiding Education Reform (TIGER) Initiative that is working to transform the nursing profession in the United States, and to make it a full partner in the national health information technology agenda. This initiative responds to the call sounded by the IOM for safer, higher-quality health care and for a core set of competencies-patientcentered care, interdisciplinary teams, evidence-based practice, quality improvement, and informatics-for all health professionals [14]. Informatics is the enabler that makes the other competencies possible. As leading institutions have demonstrated, it holds the power to link education to real events in practice, and to link clinical practice to the most relevant and most recent scientific knowledge.

A member of the IOM's committee to recommend the computer-based patient record as ,an essential technology for health care" in 1991 [15], I felt that one of the committee's biggest triumphs was to call it that, and not 'the medical record', the term then most commonly used. Subsequent work by the IOM in 'To Err Is Human' (1999) and 'Crossing the Quality Chasm' (2001) has taken this concept further, identifying patientcenteredness as one of the key attributes of a safer, higher-quality health system. Of course, health care professionals have always known that their mission is to serve the patient, but too often this mission is obscured by technology issues and system concerns, putting patients at risk. The move toward personal health records puts patients firmly at the center of health care; this new found control and knowledge will confer new responsibilities on patients and require new roles for the clinicians who are their caregivers.

If these efforts succeed, health care will truly be transformed - and we will have realized the vision that IMIA and its 18 working groups have so long advocated.

\subsection{Early IMIA Years}

The Capetown meeting was not my first IMIA experience. That occurred in 1974, when I attended the first international congress sponsored as part of an IFIP meeting and by what is now IMIA. That meeting was brought about by François Grémy, who in 1968 brought together early informaticians into IFIP's Technical Committee 4, as mentioned before, the organizational and intellectual predecessor to IMIA. He was instrumental in recruiting the first generations of IMIA officers and members from the medical and health care communities, individuals who became some of my closest and trusted friends and advisors. As I mentioned earlier, Don Lindberg, one of my mentors, was the US representative to IFIP and then to IMIA, until the fall of 1984 when he became the Director of the National Library of Medicine.

What Grémy began, Jan Roukens continued. The European Federation of Medical Informatics (EFMI) was formed and, in 1979 (the year we met in Capetown), IMIA was formally established by IFIP, with specific bylaws giving it a measure of autonomy, and Roukens was elected president (Table IV). In his view, IMIA succeeded by giving its members a framework for scientific discussion and creating an intellectual domain for health informaticians - a home where there had been none before.

David Shires, who became President in 1980 , reached out to form agreements with the regional group now know as IMIA-LAC (Latin American Countries) and the People's Republic of China (PRC), making them active participants in IMIA and forging new bonds with the World Health Organization. Today IMIA reflects Shires' goals for his presidency in its international constituency, which goes „beyond the EuropeNorth America-Japan axis to a much greater world vision" [16]. Currently there are 55 member countries working with IMIA.

In 1983, Hans Peterson assumed the presidency. „What I remember best,“ he said later, „is that there was no money." He and his fellow officers provided IMIA with free services, from printing and stationery to mailing and telephones, making it possible for the organization to survive. As he saw it, ,an international body free from political and governmental influence is absolutely necessary. In this body we have to cooperate also with the industry and get a mutual understanding that cooperation is the only way out." This vision of cooperation is a dream that has yet to be realized.

Shigekoto Kaihara became President in 1986, intent on highlighting the rel- 
evance of medical informatics to developing countries. When plans to hold the 5th MEDINFO in Beijing were threatened by events in Tien-an Men Square, he ensured that IMIA would survive by holding a two-part congress. The work of the Chinese organizing committee was realized at MEDINFO Beijing, and Dr. K.C. Lun stepped in to arrange MEDINFO Singapore. Both MEDINFOs succeeded, and IMIA gained visibility in the Asia Pacific. This could not have happened without Dr. Kaihara's extraordinary support and diplomacy.

For Jos L. Willems (during whose presidency I was President Elect), the challenge was to support IMIA's activities by changing it from a volunteer organization to one that was professionally run. As he saw it, „IMIA needs a paid executive secretary and secretariat if the organization wants to grow." He laid the groundwork for transforming IMIA organizationally and intellectually, bringing about publication of the first 'Yearbook of Medical Informatics' and gaining official recognition as NonGovernmental Organization to the World Health Organization. His untimely death shortly after his presidency was a loss to our field and to many of us personally.

\subsection{My Years as IMIA President}

At the conclusion of MEDINFO 92 in Geneva, I received the gavel from Jos Willems. Like Hans Peterson and Shigekoto Kaihara, I soon faced a crisis when Brazil withdrew as the site for MEDINFO 95. Like them, I turned to my colleagues and the IMIA membership, and Canada took on the challenge of hosting an international congress with only two years' lead time, thanks to Kathryn Hannah and Steve Huesing. With the guidance of the board, IMIA distributed governance to five new vice

Table IV IMIAPresidents

\begin{tabular}{|l|l|l|}
\hline \multicolumn{3}{|c|}{ IMIA Presidents } \\
\hline $1968-1975$ & François Grémy & France \\
$1975-1980$ & Jan Roukens & the Netherlands \\
$1980-1983$ & David B. Shires & Canada \\
$1983-1986$ & Hans Peterson & Sweden \\
$1986-1989$ & Shigekoto Kaihara & Japan \\
$1989-1992$ & Jos L. Willems & Belgium \\
$1992-1995$ & Marion J. Ball & USA \\
$1995-1998$ & Otto Reinhoff & Germany \\
$1998-2001$ & Jan van Bemmel & the Netherlands \\
$2001-2004$ & KC Lun & Singapore \\
$2004-2007$ & Nancy Lorenzi & USA \\
$2007-2010$ & Reinhold Haux & Germany \\
\hline
\end{tabular}

presidents and implemented Jos Willems' vision of a professionally-run organization with a permanent secretariat. To make IMIA a bridge organization across sectors and regions, I worked to create institutional memberships, make IMIA more visible in the USA and foster working conferences. I was also able to lend support to the Asia Pacific Association for Medical Informatics (APAMI), newly and successfully formed by $\mathrm{KC}$ Lun.

For me, IMIA was (and still is) a wonderful avenue to meet new people. As President, I was able to do outreach to the various countries where our board meetings were held. From the outset, with insights gained from the strategic planning process headed up by Hans Peterson, I had ambitious plans for my presidency. With the support of the board, we were able to make substantive progress in key areas, including strengthening IMIA organizationally and fostering health informatics regionally. In more than one instance, realizing my goals meant fulfilling the dreams held by earlier presidents, making IMIA a stronger organization by redesigning the executive board, putting IMIA on sound financial footing, and reaffirming IMIA's status in the World Health Organization.
As IMIA's first President from the USA, I was determined to give IMIA more visibility in the USA and the Americas. During my Presidency, IMIA sponsored four working conferences in the USA. One of these focused on organizational issues, one on nursing informatics, and a third on hospital information systems. The fourth, which I co-chaired, focused on health professional workstations; its findings have served as a roadmap for many of the advances made in the years since then. I am happy to report that these meetings encouraged a number of my fellow countrymen to become involved in IMIA working groups and that, as the representative of the American Medical Informatics Association (AMIA) to IMIA, I was able to bring AMIA and IMIA closer together.

In supporting regionalism, the spring 1995 board meeting was held in conjunction with InfoMedica, sponsored by the Mexican Medical Informatics Association and IMIA-LAC, and IMIALAC obtained funding from the Kellogg Foundation for 19 Latin American fellows to attend MEDINFO in Vancouver, Canada. I and my fellow board members also did all we could to support informatics in Africa. The designation of Helina as its regional 
Kaihara et al.

group came after my presidency, but I am proud to have been involved in encouraging its advocates and look forward to attending MEDINFO 2010 in Capetown. Recent developments as a result of a meeting in January 2007 in Mali have solidified Helina, and Sedick Isaacs has accepted the first presidency. My three years as IMIA President were rewarding for me personally and professionally, offering me new worlds of opportunity and friendship. Since I first became involved with IMIA and most especially during my presidential years, I grew ever more aware of the extent to which collaboration and the help of dedicated individuals make success possible. I owe my heartfelt thanks to Morris Collen and Don Lindberg, my personal mentors for almost half a century, and to my IMIA advisers and colleagues, Hans Peterson, François Grémy, Jan van Bemmel, Shigekoto Kaihara, Jean Raoul Scherrer, Otto Rienhoff, Kathryn Hannah, Judith Douglas, Steve Huesing, John Tresling, Gerd Griesser, Carl Theo Ehlers, Jochen Dudeck, and Reinhold Haux. All helped my presidency the success it was, and the Vancouver MEDINFO, the largest and most successful MEDINFO until that time.

Above all, I want to thank my husband, Dr. John Ball, and my two children, Dr. Charles Ball and Elizabeth Ball Concordia, and also my parents, now deceased, Dr. Ernst Jokl and Erica Jokl, who helped John with Charles and Elizabeth. Their support made it possible for me to be on travel and away from home to fulfill my many IMIA obligations over the years.

The depth of my gratitude is profound. My years in IMIA gave me friendship and brought the future into focus for me. My presidency helped me to understand that fundamental changes were taking place, that a new infrastructure will give us the capability to re-invent health care, if we build bridges across regions, disciplines, and professions, to bridge the distances around the globe. The IMIA presidents who followed me-Otto Reinhoff, Jan van Bemmel, KC Lun, Nancy Lorenzi, and now Reinhold Hxome. We pursue our professions as health informaticians in exciting times. They are not without danger, but we will create the successes that will move us and health care forward. When IMIA convenes its next MEDINFO after Australia in Capetown in 2010, it will be thrilling indeed if we have come full circle and realized the vision we put forth there almost 30 years ago. Let us all work together as we had dreamed to do, and harness the technology to help put the ill at ease around the globe.

\subsection{Acknowledgements}

These reminiscences are dedicated to the memory of those leaders in the International Medical Informatics Association (IMIA) who are no longer with us: Carl Theo Ehlers, Gerd Griesser, Peter Reichertz, Jean Raoul Scherrer, and Jos Willems. We owe them our gratitude for the guidance they gave us, and we miss them.

\section{Jan van Bemmel, The Netherlands, IMIA President 1998-2001}

The International Medical Informatics Association (IMIA) has been established in the 1970s by individuals who were already active in medical information processing in their home countries. At that time, the term 'informatics' (from the French 'informatique' or Latin 'informatica') was not yet in existence. IMIA was founded by very motivated individuals and bears no characteristics of a company or some governmental organization. Its members are national member organizations or institutions in medical, health, or nursing informatics. In the beginning most of the early founders came from universities and research organizations.

\subsection{Raising Interests}

My interest in the upcoming field of medical informatics was much reinforced after having attended in 1966 the very first European conference on computers in medicine, held in Elsinore, Denmark. This conference, at that time without parallel sessions, was held close to the very same place where Hamlet spoke the famous words: '2B or not $2 \mathrm{~B}$ '. It was in Elsinore where I met for the first time people like Hubert Pipberger and Cesar Caceres, who had started a few years earlier the computer processing of electrocardiograms. From then on I collaborated closely with Hubert over many years. Making international bridges is one of the great advantages of an association like IMIA. Junior researchers are able to meet and start collaboration with more experienced people, from all over the world. This is the very reason why IMIA should keep organizing working conferences and MEDINFO world conferences. In a way, they can be considered as market places, where knowledge and experience are being exchanged and 'traded'.

\subsection{TC-4}

Having myself in 1963 started using computers for biomedical research and clinical applications, I received in 1967 a grant from WHO to describe the state of affairs of computers in European hospitals. I made a long study tour 
along hospitals and research laboratories and wrote a comprehensive report called 'Computers in European Hospitals'. It was during this study tour to several European cities (from Geneva and Paris to Stockholm and London) that I met for the first time François Grémy in Paris. Since then I never lost contact with François, and just over one year ago I visited him again with Marion Ball in the south of France. He too, just like me, was very interested in using computers, foremost for biomedical research. Therefore, François joined the International Federation for Information Processing (IFIP), and chaired the so-called Technical Committee 4 (TC4) for medical information processing. This TC-4 became the forerunner of IMIA, which was established in 1977 , also based on the success of the first medinfo conference in Stockholm. François can be considered IMIA's first President, from 1968-1975, even before the field of 'medical informatics' was invented and IMIA was established.

\subsection{Activities in IMIA}

In the mean time, we established in 1970 in the Netherlands one of the first European professional societies in medical informatics, the Vereniging (Society) for Medical and Biological Information processing, VMBI. Jan Roukens became its first chairman and I became its second. Having done so, the VMBI quickly joined TC-4 of IFIP, and Jan Roukens became also part of it, succeeding François Grémy as its second President, now called IMIA. From the very beginning I took part in those early activities, including the first world conference for medical information processing, medinfo 74, in Stockholm. After this first medinfo conference, I have been active in all following medinfos, such as the editing of the Proceedings of medinfo 83 in Amsterdam, together with Marion Ball and Ove Wigertz, and chairing the scientific program committee, together with Ted Shortliffe, of medinfo 86 in Washington DC. Over the years I had the privilege of organizing several working conferences and editing several books in the framework of IMIA (see the short list [17] - [25] in the references). A most interesting period was the editing of IMIA's Yearbooks, a job done together with Alexa McCray, and with the help of many other colleagues, during the years 1992-2000. Since then, Reinhold Haux and Casimir Kulikowski have taken over the Yearbooks.

In 1998 I took over the helm to steer the ship of IMIA for a period of three years, after François Grémy and his successors, all of them IMIA presidents for a period of three years: David Shires, Canada; Hans Peterson, Sweden; Shigekoto Kaihara, Japan; Jos Willems, Belgium; Marion Ball, USA; and Otto Rienhoff, Germany. Under Hans Peterson's leadership, the rules for IMIA and MEDINFOs have been documented in its Standing Orders. This reshaped IMIA to a genuine professional organization.

\subsection{Dynamic Changes}

As said, some of us have experienced the entire period of medical and health/ nursing information processing and have seen that over the years the field has changed fundamentally. In the beginning, all activities centered round large central information systems that gave support to the infrastructure of health care institutions (e.g., hospital information systems). At that same early time, attention was paid to smaller, but special-purpose systems, such as for clinical laboratories or biosignal processing. Later, the field was extended to include medical image processing and knowledge processing. Gradually, also networking and electronic communication came into play, and we are now in the middle of another wave of changes: communication and integration, and the support of patient care, reflected in the worldwide focus on computer-based patient records. In recent years, some departments have changed their name into 'biomedical informatics' to reflect the merging with bio-informatics, a prefix that was already incorporated in the name of the Dutch VMBI. The next wave will merge knowledge processing with electronic patient records. IMIA has to prepare itself for such changes.

\subsection{Own Presidency}

Let me tell you a little about my presidency, which started in Seoul, Korea, and ended in London, UK. First of all, let me quote the song (Panel I) that I wrote and that was performed by about 50 of IMIA's officials at the great conference dinner during MEDINFO 98 in Seoul.

During the period 1998-2001, I defined a short agenda for IMIA, having a roadmap in mind, consisting of the following elements:

1 Strengthen IMIA as professional organization;

2 Build bridges to other organizations;

3 Tap the experience of former officers and honorary members;

4 Make IMIA better visible to the outside world;

5 Make MEDINFOs still better and MEDINFO 2001 the largest ever.

\section{IMIA's Permanent Office}

During my serving IMIA, and after thorough preparations in the preceding years, we established a true Permanent Office, which appeared to become of paramount importance. The goal of IMIA's Permanent Office is to keep the memory of IMIA, to give service to its 
Kaihara et al.

\section{Panel I Song by IMIA}

\section{Song by IMIA officials at MEDINFO 98 in Seoul}

(melody: the Russian Stenka Razin, see

www.musicarussica.com)

Here we stand, the famous Cossacks, we belong to IMIA.

We use lots of large computers and we sing an aria.

Working groups and conferences are the reasons that we meet. We develop many systems coding SNOMED, also READ

Publications in the Yearbook make us famous ev'rywhere; with a lot of self-citations, serving better patient care.

Informatics is our business, data storage our pursuit. But clinicians do not take it that our systems are that good

We develop knowledge bases, accessed through the Internet. But the experts do not use them; they don't trust us, which is bad.

We need science - more than systems for advancing IMIA creativity is needed, merged with informatica.

Data, knowledge, information are the core of IMIA, but its heart is formed by people, meeting in harmonia. Here we stood, the famous Cossacks, we belong to IMIA. We use lots of large computers and we sang our aria.

members and others, and to raise resources for IMIA. The IMIA Office is now involved in:

- giving assistance to IMIA's Board and General Assembly,

- long-range planning; preparation of policy and its execution,

- with member societies, working groups, and affiliated societies,

- facilitation of regional and working conferences, consultation activities, and MEDINFOs,

- contacts with and giving service to industrial and academic institutional members,

- publications, newsletters, Yearbooks, conference proceedings, etc.,

- promoting medical/health/nursing informatics to industry,

- raising financial resources from IMIA services and activities.

IMIA's website www.imia.org became the central vehicle for the IMIA Secretariat. It forms the means to communicate with IMIA's working groups and national and institutional members. Steven Huesing became the Executive Director of IMIA, and it was a great pleasure closely working with him.

\section{Building Bridges}

I still see a great role for IMIA as a 'bridge' organization both within an inter-organizational context and within the broader context of IMIA's professional aims. Within this professional context, for instance, the concept of a 'virtual university', led by Evelyn Hovenga, Australia, took root. IMIA's Institutional Members, both Academic and Corporate, grew to record numbers, in particular because of the unrelenting activities of Marion Ball. In addition, IMIA's efforts to include scientists, researchers and educators in developing countries were extremely successful in that corresponding memberships increased dramatically.

\section{Tap the Experience of Professionals}

It was the intention that the experience of senior officers and honorary members would be better tapped when they would be more involved in reflecting on plans of IMIA's Board. They can come forward with ideas for long-range planning; give advice on a model for accreditation of persons and institutions by IMIA, and reflect on the suggestion of establishing a group to be called 'friends of IMIA'.

Fig 1 Stormy weather, experienced by Dutch participants, when crossing the North Sea from London to Rotterdam, after having attended MEDINFO 2001, by the tall sailing ship Artemis (1,100 square meters of sail)

\section{MEDINFOs}

At the end of my presidency, MEDINFO 2001 took place in London at a very new venue in the Docklands. The conference was a great success, although not as many attendants were present as expected. Participants from my department in Rotterdam traveled by a tall sailing ship (1,100 $\mathrm{m} 2$ of sail!) from Rotterdam to London (Figure 1). In London I handed the gavel to my successor, K.C. Lun from Singapore. The picture gives a view on the rough seas we met when sailing back to our home port, Rotterdam. Perhaps, such seas are representative for the storms with which IMIA is sometimes confronted.

\subsection{Acknowledgements}

During my presidency, it was a privilege to work closely together with many colleagues, in particular in IMIA's Board, from all over the world: Ian Symonds (New Zealand), Secretary; John Tresling (South Africa) and Ulla Gerdin (Sweden), both as Treasurers; K.C. Lun (Singapore), Vice President for MEDINFOs and my successor as IMIA's President; Alexa T. McCray (USA) and Reinhold Haux (Germany),

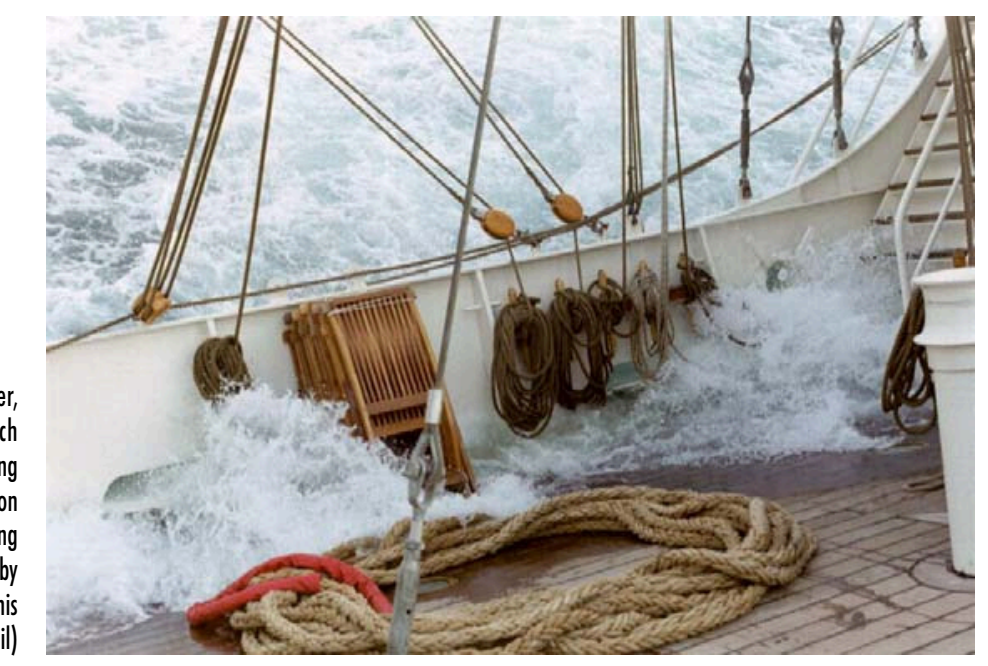


Vice Presidents for Services; Jean Roberts (UK) and Branco Cesnik (Australia), Vice Presidents for Members; Nancy Lorenzi (USA), Vice President for SIGs and WGs and IMIA President after K.C. Lun; Brian Shorter (UK), Vice President for Special Activities; Marion Ball (USA), my predecessor as IMIA President and Liaison Officer to the NLM; Patrice Degoulet (France), Liaison Officer to the EU; Jean-Raoul Scherrer (Switzerland), Liaison Officer to HON and IFIP; and Steven Huesing (Canada), IMIA's Executive Director. I am most thankful for their friendship and support.

\section{References}

1. www.IMIA.org

2. Lorenzi N. Strategy in a fishbowl: an invitation to determine the shape of IMIA in 2015. Methods Inf Med 2006;45:235-9.

3. Lorenzi N. Towards IMIA 2015 - the IMIA Strategic Plan. In: Geissbuhler, Haux R, Kulikowski C, editors. 2007 IMIAYearbook of Medical Informatics. Methods Inf Med 2007;46: xx-xx

4. Degoulet P, Haux R, Kulikowski C, Lun KC. François Grémy and the birth of IMIA. Methods Inf Med 2005;44:349-51.

5. Peterson HE. From Punched Cards to Computerized Patient Records: A Personal Journey In: Haux R, Kulikowski C, editors. 2006 IMIA Yearbook of Medical Informatics. Methods Inf Med 2006; 45:S180-6.

6. Institute of Medicine. Crossing the quality chasm: A new health system for the 21st Century. Second and final report of the Committee on the Quality of Health Care in America. Washington, DC: National
Academy Press; 2001.

7. Shannon RH, editor. Hospital information systems: An international perspective on problems and prospects. Proceedings of the IFIP working conference on hospital information systems, Capetown, South Africa, 2-6 April 1979. Amsterdam: North-Holland Publishing Company; 1979.

8. Ball MJ. Concluding remarks. In: [7], 393-394.

9. Ball MJ, Silva JS, Douglas JV, Degoulet P, Kaihara $\mathrm{S}$, editors. The health care professional workstation. Proceedings of a working conference sponsored by the International Medical Informatics Association, Washington, DC, USA, 14-16 June 1993. Published as a special issue of the Int J Biomed Comput 1994;34:1-415.

10. For more information, visit www.tigersummit.com.

11. IBM. 2006. Healthcare 2015.

12. Ball MJ, Douglas JV. 2005. Human Factors: Changing Systems, Changing Behaviors. Chapter 6 in Person-Centered Health Records: Toward Healthier People. Demetriades JE, Kolodner RM, Christopherson GA, editors. New York: Springer; 2005. p. 60-70.

13. Braude RM. People and Organizational Issues in Health Informatics. JAMIA; 1997:4:150-1

14. IOM. Health Professionals Education: A Bridge to Quality. Washington, DC: National Academy Press; 2003

15. IOM. The Computer-based Patient Record: An Essential Technology for Health Care. Washington, DC: National Academy Press; 1991

16. Ball MJ. Bridging to New Worlds: Reflections on the IMIA Presidency 1992-1995; 1995

17. Van Bemmel JH, Willems JL, editors. Trends in computer-processed electrocardiograms. Amsterdam: North Holland Publ Comp, 1977.

18. Van Bemmel JH, Ball MJ, Wigertz O, editors. MEDINFO-83. Amsterdam: North Holland Publ Comp; 1983.

19. Willems JL, van Bemmel JH, Zywietz C, editors. Computer ECG Analysis: Towards Standardization. Amsterdam: North Holland Publ Comp; 1985.

20. Van Bemmel JH, Grémy F, Zvárová J, editors. Medical Decision Making: Diagnostic Strategies and Expert Systems. Amsterdam: North Holland Publ Comp; 1985.

21. Willems JL, van Bemmel JH, Michel J, editors.
Progress in Biological Function Analysis. Amsterdam: North Holland Publ Comp; 1988.

22. Van Bemmel JH, Lindberg DAB, Grémy F, Shortliffe EH, Wigertz O, editors. Data, Information, Knowledge in Medicine, Developments in Medical Informatics in Historical Perspective. Methods Inf Med 1988; 27 (special issue).

23. Van Bemmel JH, Zvárová J, eds. Knowledge, Information and Medical Education. Amsterdam: Elsevier Science Publ; 1991.

24. Van Bemmel JH, Rosenfalck A, Saranummi N, editors. Biosignal Interpretation. Methods Inf Med 1994; 33 (special issue).

25. Van Bemmel JH, McCray AT, editors. IMIA Yearbooks of Medical Informatics. Stuttgart: Schattauer Verlag, 1992-2000.

\section{Addresses of the authors:}

Marion J. Ball, Ed.D.

IBM Research

Center for Healthcare Management

Professor, Johns Hopkins School of Nursing

Baltimore, MD 21210

USA

E-mail: marionball@us.ibm.com

Jan H. van Bemmel, PhD

Institute of Medical Informatics

Erasmus Medical Center and

Erasmus University Rotterdam

Dr. Molewaterplein 50

P.O. Box 2040

3000 CA Rotterdam

The Netherlands

E-mail: J.vanBemmel@ErasmusMC.nl"

Shigekoto Kaihara MD, PhD

Dean Graduates School

International University of Health and Welfare

Aoyama-lchome Tower

4F1-3-3 Minami-Aoyama

Minato-Ku, Tokyo 107-0062

Japan

E-mail: kaihara-tky@umin.net 